\title{
ROL DE LOS RECEPTORES NICOTÍNICOS DE ACETILCOLINA EN MECANISMOS DE DOLOR
}

\author{
THE NICOTINIC RECEPTORS AND THEIR ROLE IN THE PAIN \\ MECHANISMS
}

Jérez-Escobar Javier ${ }^{1}$

Martínez-Visbal Alfonso²

Correspondencia: fonsomartinez@gmail.com

Recibido para evaluación: febrero-29-2015. Aceptado para publicación: mayo-5-2015.

\section{RESUMEN}

Introducción: los receptores nicotínicos de acetilcolina (nAChR) en el estudio y entendimiento del dolor se han evaluado ampliamente en las últimas dos décadas. Se consideran piezas importantes para el desarrollo de analgésicos.

Objetivo: identificar conceptos y avances acerca de los nAChR y su papel en la modulación del dolor.

Metodología: se realizó búsqueda en PubMed, MEDLINE, ScienceDirect, Scielo, OvidSP, EBSCOhost y en la Biblioteca Cochrane (incluyendo la base de datos Cochrane de revisiones sistemáticas y Cochrane controlled trials register). También en las plataformas de las Revistas JAMA, Lancet, New England Journal of Medicine y Anesthesiology. Las búsquedas se limitaron a los idiomas inglés y español, así como documentos publicados entre 1970 y 2015.

Resultados: los nAChR son canales iónicos transmisores que constan de diferentes subtipos, cada uno de los cuales tiene una farmacología y fisiología específica, con diferente distribución anatómica en el cerebro. No se limitan solo a sitios postsinápticos, también se localizan a nivel pre, peri y extrasinápticos donde pueden modular la función neuronal por una variedad de acciones. Los nAChR neuronales difieren de los nAChR periféricos, ya que no tienen las subunidades $Y, \delta, \varepsilon o$, en su confección y constan de varios complementos de a2-a9 y subunidades $\beta 2-\beta 4$. Actualmente, seis $a$ ( $a 2-$ a7) y tres $\beta$ ( $\beta 2-\beta 4)$ subunidades se han identificado y clonado a partir de cerebro humano. Los nAChRs son interesantes para develar los mecanismos inherentes al dolor y desarrollar nuevos analgésicos. Los ligandos a nAChR a4ß2 siguen siendo la estrategia más atractiva para explicar el dolor neuropático e inflamatorio. Subunidades nicotínicas a5 reducen los estados de dolor e inflamación sobre todo neuropática. La activación central y periférica del nAChR a7, reduce la nocicepción y el dolor inflamatorio agudo. Conclusión: se observan avances en el conocimiento de los nAChR en los mecanismos del dolor. Amplios estudios se realizan a nivel preclínico para desarrollar nuevas estrategias terapéuticas y antiinflamatorias. Rev.cienc.biomed. 2015;6(1):118-129

\section{PALABRAS CLAVE}

Receptores nicotínicos; Dolor; Dimensión del dolor; Clínicas de dolor; Percepción del Dolor; Hiperalgesia.

Médico. Estudiante de postgrado. Anestesiología. Universidad del Sinú. Seccional Cartagena. Cartagena. Colombia.

Médico. Anestesiólogo y Algesiólogo. Profesor. Universidad de Cartagena. Universidad del Sinú. Seccional Cartagena. Cartagena. Colombia. 


\section{SUMMARY}

Introduction: The nicotinic acetylcholine receptors (nAChRs) in the study and understanding of the pain have been evaluated widely in the last two decades. They are considered as important pieces for the development of analgesics.

Objective: To identify concepts and advances about the nAChRs and their role in the pain modulation.

Methods: A search in the databases PubMed, MEDLINE, ScienceDirect, Scielo, OvidSP, EBSCOhost and in the Cochrane library (including the database Cochrane of systematic reviews and Cochrane controlled trials register) was done. Also the journals JAMA, Lancet, New England Journal of Medicine and Anesthesiology were reviewed. The searches were limited to English and Spanish and to the period between 1970 and 2015. Results: The nAChR are ionic channels transmitters that consist of different subtypes, each of which has a pharmacology and specific physiology, with different anatomical distribution in the brain. They are not limited only to postsynaptic sites and also are located to level pre, peri and extrasynaptic sites where they can modulate the neuronal function for a variety of actions. The neuronal nAChR differ of the peripheral ones due to they do not have the subunits $Y, \delta, \varepsilon O$, in their confection and they consist of several complements of $a 2-a 9$ and subunits $\beta 2-\beta 4$. Currently, six a (a2-a7) and three $\beta(\beta 2-\beta 4)$ subunits have been identified and cloned from human brain. The $n A C h R s$ are interesting to reveal the mechanisms inherent to pain and to develop new analgesics. The ligand to $n A C h R$ a $4 \beta 2$ continue being the most attractive strategy to explain the neuropathic and inflammatory pain. Nicotinic subunits a5 reduce the pain and inflammation of neuropathic predominance. The central and peripheral activation of the $n A C h R$ a7 reduces the nociception and the acute inflammatory pain.

Conclusion: Advances in the knowledge of the $\mathrm{nAChR}$ in the pain mechanisms are observed. Wide studies are carried out to preclinical level to develop new therapeutic and anti-inflammatory strategies. Rev.cienc.biomed. 2015;6(1):118-129

\section{KEYWORDS}

Nicotinic receptors; Pain; Pain measurement; Pain clinics; Pain perception; Hyperalgesia.

\section{INTRODUCCIÓN}

Aunque los Receptores Nicotínicos de Acetilcolina o Neuronal Nicotinic Acetylcholine Receptors (nAChR), en el estudio y entendimiento del dolor no han sido descritos a profundidad, en las últimas dos décadas se han intensificado los estudios al respecto. La existencia de vínculo entre la nicotina y la analgesia, no es una afirmación nueva (1).

La nicotina es un alcaloide natural, sintetizada por varias plantas de la familia de las Solanaceae, que incluyen: patatas, berenjenas, pimientos verdes y la planta del tabaco. La planta del tabaco cultivada durante siglos por los nativos de América del Sur y más tarde América del Norte, se ha utilizado como hierba curativa y para rituales. Esta planta se introdujo en Europa en el siglo XVI por Jean Nicot De Villemain, embajador francés en Portugal, quien llevo en 1560 las plantas de tabaco a París. El uso del tabaco, Nicotiana tabacumwas, en Catalina de Médicis, para tratar el dolor de cabeza fue exitoso. Por tanto fue rápido el crecimiento en cuanto a su uso en muchos países y la costumbre de su administración se extendió progresivamente en la población (2).

En el mismo siglo, Oviedo y Valdés, historiador español, informó por primera vez que el tabaco aliviaba el dolor causado por la sífilis (3). A mediados del siglo XVII cerca de la mitad de los hombres adultos en Inglaterra consumían tabaco a diario, sobre todo para masticar o en pipas. Posteriormente se hizo posible su consumo en cigarrillos, los cuales se comenzaron a producir en masa. Fumar cigarrillos aumentó abruptamente en el siglo XX. Debido a la gran eficacia de las campañas de publicidad, se produjo expansión del mercado, lo que llevó a la pandemia de dependencia a la nicotina del mundo actual (4). Sin embargo, en ese siglo la nicotina no se miraba como benéfica para la analgesia, hasta que se encontró la aplicación para producir antinocicepción en gatos (5). El objeti- 
vo de la revisión fue identificar conceptos y avances acerca de los nAChR y su papel en la modulación del dolor.

\section{METODOLOGÍA}

Tipos de estudio: revisión temática y descriptiva en la que se incluyeron revisiones sistemáticas, investigaciones originales, editoriales, revisiones de tema, meta-análisis, opiniones y comentarios.

Tipos de participación: documentos científicos sobre receptores nicotínicos de acetilcolina, su papel en las vías del dolor y su mecanismo de acción con los diferentes analgésicos estudiados.

Estrategia de búsqueda bibliográfica: se realizó una búsqueda en PubMed, MEDLINE, ScienceDirect, Scielo, OvidSP, EBSCOhost, la Biblioteca Cochrane (incluyendo la Base de Datos Cochrane de Revisiones Sistemáticas y Cochrane Controlled Trials Register), y en las plataformas de las Revistas JAMA, Lancet y New England Journal of Medicine, Anesthesiology, entre otras. Las búsquedas se limitaron a los idiomas inglés y español, así como documentos publicados entre 1970 y 2015.

Términos claves: fueron tomados del DeCS los siguientes descriptores: receptores nicotínicos de acetilcolina, vías del dolor, modulación del dolor, dolor agudo y crónico, dolor inflamatorio, hiperalgesia; así como su respectiva traducción al inglés.

Métodos de revisión: se estudiaron títulos, resúmenes y textos completos de los documentos seleccionados en las bases de datos consideradas. Si los resúmenes se ajustaban a las exigencias del objetivo planteado, se trataban de obtener los artículos completos. Se consideraron artículos completos a conveniencia.

Recopilación y análisis de datos: se revisaron artículos completos de forma independiente.

\section{RESULTADOS}

Se encontraron 1613 artículos publicados en diferentes revistas, de los cuales 81 docu- mentos completos fueron escogidos a conveniencia para extracción de la información relevante y ajustada a los objetivos planteados.

\section{Receptores nicotínicos}

En 1921 Otto Loewi observó que el nervio vago liberaba una sustancia que disminuía la velocidad de los latidos de un corazón de rana. Además, si el líquido de este corazón se transfería a otro, se reproducía el mismo efecto inhibitorio. Loewi describió esta actividad como transmisión humoral. Posteriores experimentos demostraron que la sustancia liberada era la acetilcolina y que sus efectos podían observarse en otros tejidos (6). En 1934 Sir Henry Dale clasificó estos efectos farmacológicos como "muscarínicos" o "nicotínicos", según fueran reproducidas por los alcaloides muscarina o nicotina, respectivamente (7). Durante la década de los noventa y gracias a la aplicación de técnicas de biología molecular, se han clonado e identificado distintos subtipos de receptores colinérgicos: nicotínicos y muscarínicos (8).

Los nAChR son canales iónicos transmisores que constan de diferentes subtipos, cada uno de los cuales tiene una farmacología y fisiología específica, con diferente distribución anatómica en el cerebro $(9,10)$. No se limitan solo a sitios postsinápticos, también se localizan a niveles pre, peri y extrasinápticos, donde pueden modular la función neuronal por una variedad de acciones (11). Pertenecen a la superfamilia de genes de canales iónicos activados por ligandos, de los cuales AChR musculares son el prototipo, que también incluye: GABA, glicina y 5-hidroxitriptamina (12).

11 genes que codifican para subunidades de nAChR se han clonado hasta ahora. Al igual que todos los otros miembros de la superfamilia de canales iónicos ligandos, genes de la subunidad nAChR codifican para péptidos que tienen una porción amino terminal extracelular relativamente hidrófila, seguidos de tres dominios hidrofóbicos transmembrana [MI-M3], un bucle intracelular grande y dos dominios transmembrana hidrófobo [M4] $(13,14)$.

Las once subunidades han sido clasificadas en dos subfamilias de ocho subunidades a y 
tres subunidades $\beta$. Las subunidades a tienen dos cisteínas adyacentes que son homólogas y están presentes en las posiciones 192 y 193 de la subunidad a de AChR de tipo muscular, donde tienen afinidad marcada por los agonistas y antagonistas colinérgicos y participan en la formación de sitios de unión de agonistas. La subunidad a del músculo se conoce como a1, y los ocho subunidades a neuronales como a2-a9; estos representan las subunidades de unión agonista (15). Las subunidades $\beta$ ( $\beta 2-\beta 4)$ carecen de la par de cisteínas adyacentes y se consideran subunidades estructurales, aunque se ha demostrado claramente que ambas subunidades a y $\beta$ contribuyen a la especificidad farmacológica de los subtipos de AChR (16). Además, los $\mathrm{nAChR}$ neuronales están involucrados en una serie de procesos funcionales que incluyen la cognición, el aprendizaje y la memoria, la excitación, el flujo sanguíneo cerebral y el metabolismo y una lista creciente de condiciones patológicas (17).

Estructura de los receptores nicotínicos Los nAChR periféricos y neuronales están compuestos de hetero-oligómeros que constan de cinco subunidades de membrana, los cuales se agrupan formando una estructura en forma de barril en la membrana que rodea un canal de ion central (18). Estudios de clonación molecular en polluelos, ratas y humanos han identificado varios genes que codifican diversos subtipos de subunidades que permiten el montaje de una amplia variedad de oligómeros de receptores con diferente distribución y perfiles farmacológicos distintos (19).

Los nAChR periféricos, tales como las que se encuentran en la unión neuromuscular, se componen de subunidades $a 1, \beta 1, y, \delta$, $0, \varepsilon$ (en formas adultas y fetales del receptor, respectivamente) en la estequiometría

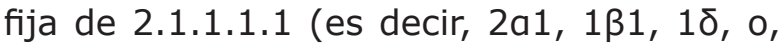
$1 \varepsilon)$. Los $n A C h R$ neuronales difieren de los de la periferia ya que no tienen subunidades $Y$, $\delta, \varepsilon, o$, en su confección y constan de varios complementos de $a 2-a 9$ y subunidades $\beta 2-\beta 4$. Actualmente, seis a (a2-a7) y tres $\beta$ ( $\beta 2-\beta 4)$ subunidades se han identificado y clonado a partir de cerebro humano $(20,21)$. Las subunidades de los nAChR neuronales se ensamblan de acuerdo con una estequiometría $2 a 3 \beta$ en general, con la posibilidad de más de una subunidad de un subtipo dentro de un pentámero (22). Sin embargo, a7, a8 y a9 subunidades son conocidos para formar homo-oligómeros funcionales que consisten en un solo subtipo de la subunidad (23).

Análisis de las secuencias de aminoácidos de los $\mathrm{nAChR}$ revelan una homología significativa entre los subtipos de nAChR neuronales y $\mathrm{nAChR}$ periféricos. En general, la secuencia del receptor nicotínico consiste en: [A] Un gran dominio amino terminal hidrófilo. [B] Un dominio compacto de división hidrófoba en tres segmentos de 19-27 aminoácidos denominados M1-M3, [C] Un pequeño dominio hidrófilo altamente variable. [D] Un dominio C terminal hidrófobo de aproximadamente 20 aminoácidos denominado M4.

La Tabla No 1 muestra la distribución de las subunidades del receptor de acetilcolina a nivel cerebral. La Figura $N^{\circ} 1$ esquematiza los diferentes tipos de nAChR neuronales. Se piensa que el dominio hidrófilo grande que contiene el amino terminal contiene sitios de fosforilación y está expuesto a la hendidura sináptica donde juega un papel en la unión del ligando. El pequeño dominio hidrófobo expuesto al citoplasma contiene sitios de glicosilación, y los cuatro dominios hidrófobos (M1-M4) comprenden los segmentos transmembrana del receptor, algunas de las cuales se alinean en el canal de iones (24).

\begin{tabular}{|l|c|c|c|c|c|}
\hline \multicolumn{7}{|c|}{ DISTRIBUCIÓN DE LAS SUBUNIDADES NEL RECEPTOR DE ACETILCOLINA } \\
DE TIPO MUSCARÍNICOS.
\end{tabular}


A.
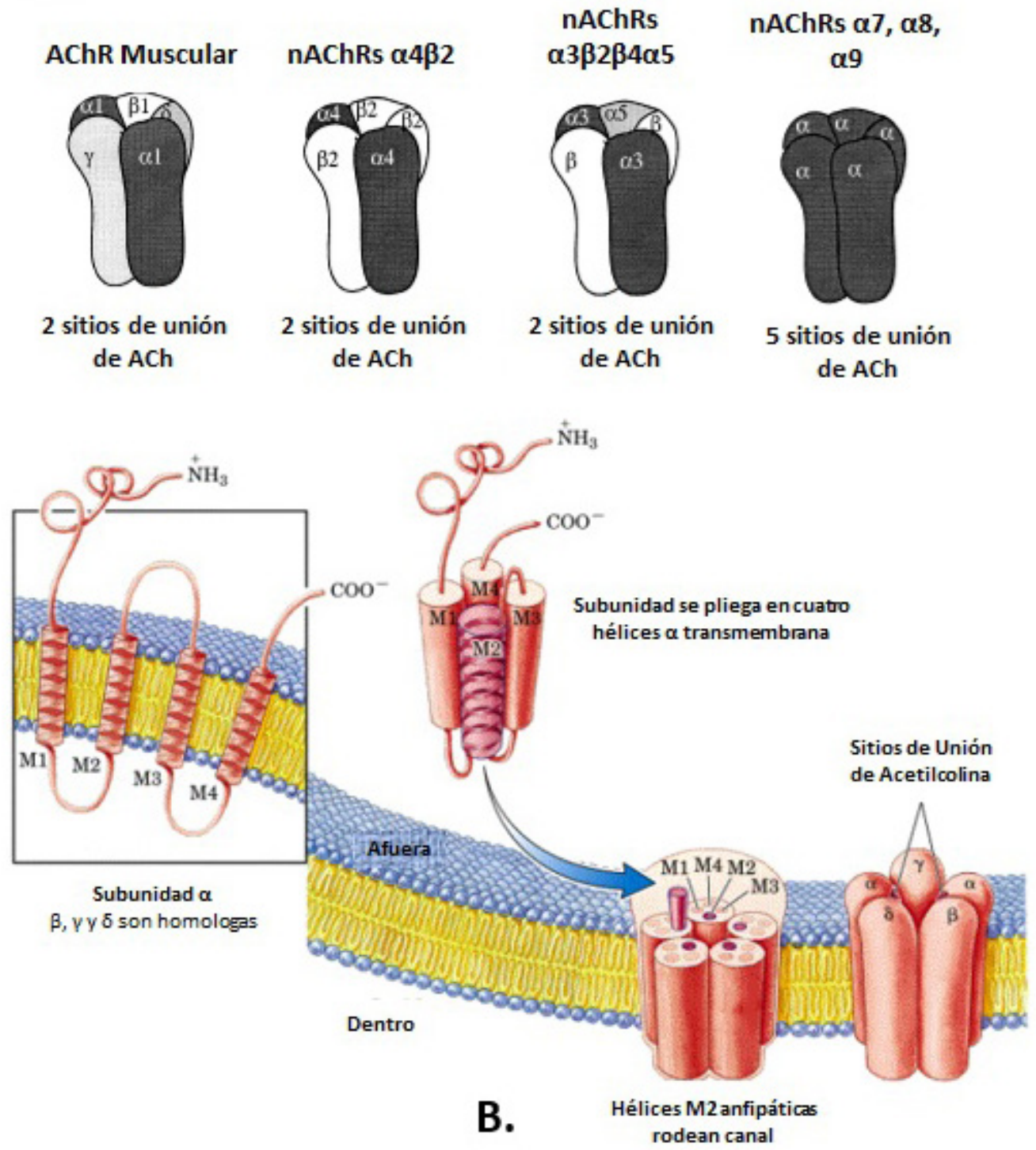

Figura No 1. La estructura del receptor nicotínico.

(A) Estructura pentamérica, subunidad de estequiometría y número de sitios de unión de tipo muscular, tipos a4 32 y a3ß2ß4a5 heteroméricos neuronal y homoméricos $a 7$, a8 y a9 de los receptores nicotínicos.

(B) Secuencia del receptor nicotínico que muestra el dominio extracelular hidrófilo que contiene el sitio de unión de ACh, cuatro segmentos transmembrana M1-M4, el dominio intracelular hidrófobo y el dominio pequeño C terminal. Destacado en la cuadrado es el segmento transmembrana M2 que se cree que forman el revestimiento del canal de iones.

\section{Receptores nicotínicos y su rol en la analgesia}

Los nAChR representan objetivos viables para el desarrollo de nuevos analgésicos. Investigaciones recientes han revelado que la microinyección de nicotina en varias regiones del tronco cerebral podría ser pronociceptiva o antinociceptivo (25). Además, la antinocicepción inducida por la nicotina puede ser bloqueada por mecamilamina, un antagonista de los nAChR neuronal no selectivo (26).
El efecto analgésico de la nicotina también se ha replicado en los seres humanos, ya que la nicotina reduce el dolor agudo experimentado a partir de una prueba de frío en fumadores y exfumadores (27). Aunque estos hallazgos apoyan el desarrollo de la nicotina como un analgésico, diferentes pruebas que han demostrado sus efectos adictivos plantearon preocupación sobre su uso $(28,29)$. Además, la administración repetida de nicotina induce tolerancia a los efectos antinoci- 
ceptivos en ratas (30). A pesar de estas preocupaciones, el enfoque en los nAChR como objetivos para el desarrollo de analgésicos se ha convertido en un área activa de investigación.

\section{nAChR a4ß2}

El subtipo de receptor nicotínico de mayor distribución en el cerebro es el receptor nicotínico de la acetilcolina heteromérico a4 $\beta 2$, insensible a-bungarotoxina (31). La nicotina actúa como un agonista y muestra una mayor selectividad hacia estos receptores. La primera evidencia que implica el nAChR neuronal $a 4 \beta 2$ en la modulación del dolor, proviene de estudios que demuestran que los ratones knockout tienen reducción del efecto antinociceptivo de la nicotina (32).

La distribución anatómica del nAChR neuronal a4ß2 en el cerebro y la médula espinal juega un papel importante en la transmisión nociceptiva $(33,34)$. La activación presináptica del nAChR a $4 \beta 2$ incrementa la liberación de múltiples neurotransmisores en el cerebro incluyendo acetilcolina, dopamina, GABA y noradrenalina (35). La Epibatidina un agonista del receptor nicotínico de la acetilcolina a4 $\beta 2$ aislado de la piel de una rana venenosa de Ecuador, demostró efectos analgésicos potentes, mejor que los opiáceos como la morfina. Sin embargo, tiene una escasa selectividad entre los subtipos de agonistas nicotínicos receptor de acetilcolina, especialmente a4 $\beta 2$ vs. receptor de acetilcolina nicotínico a3 $\beta 4$, y su perfil de toxicidad lo hizo no desarrollable para uso clínico (36). La Tebaniciclina un compuesto ABT-594 tiene una potente actividad analgésica en el manejo del dolor agudo, crónico y en dolor neuropático secundario a lesión de nervios y con menores efectos secundarios en relación a la Epibatidina $(37,38)$.

Varios sitios han sido propuestos para la acción antinociceptiva de ligandos de los nAChR neuronales $a 4 \beta 2$, incluyendo sitios espinales y supraespinales. Los nAChR a4ß2 están presentes en núcleo del rafe magnus (NRM), rafe dorsal (DR), locus coeruleus (LC) (39). Muchas de estas áreas se cree que desempeñan un papel importante en la descendente monoaminérgica inhibitoria vía del dolor. La sustancia gris periacueductal del mesen- céfalo es un componente importante de la vía inhibitoria descendente que contiene el nAChR neuronal a4 32 y media la transmisión sináptica gabaérgica (40). Varios estudios han informado de la acción analgésica de la epibatidina está mediada a través de los nAChR a $4 \beta 2$ en el NRM y las regiones LC y además median los efectos antinociceptivos de ABT-594 y A-85380 (41,42).

Además de las vías supraespinales, varias vías espinales están involucradas en la actividad antinociceptiva de a $4 \beta 2$ ligandos. En la médula espinal, la activación presináptica del nAcHR neuronal a $4 \beta 2$ ejerce inhibición tónica en la transmisión nociceptiva (43). También es importante señalar que la activación de este receptor conduce a la liberación de serotonina y norepinefrina en la médula espinal que .están implicados principalmente en la vía inhibidora descendente (44).

El sistema gabaérgico espinal también está implicado en la analgesia mediada a través de los nAChR a4ß2. La analgesia inducida por la nicotina mediada a través del receptor de acetilcolina nicotínico neuronal a $4 \beta 2$ fue bloqueado por antagonistas del GABA, sugiriendo que esté es responsable de la mejora en la transmisión gabaérgica-colinérgica espinal (45).

Los ligandos de $n A C h R$ a $4 \beta 2$ siguen siendo la estrategia atractiva para el tratamiento del dolor neuropático e inflamatorio. El dolor neuropático está asociado con daño a nervios periféricos o espinales o lesiones a la médula espinal. Mecanismos implicados en el dolor neuropático incluyen la sensibilización periférica o central, pérdida o hipoactividad de la inhibición descendente. Ligandos del nAChR a $4 \beta 2$ se evaluaron en una variedad de modelos de dolor neuropático como la ligadura parcial del nervio ciático (LPNC), lesión crónica de constricción (LCC), ligadura del nervio espinal (LNE), dolor neuropático diabético y quimioterapia inducida. El papel anti-inflamatorio de la nicotina está bien documentado, y transcripciones de receptor de acetilcolina nicotínico neuronal subunidades a4 y $\beta 2$ se han detectado en múltiples tipos de células inflamatorias (46). Hosur et al., demostraron que la nicotina suprime la expresión de citoquinas proinflamatorias tales como IL- $1 \beta$ y IL-6 a través del nAChR a4ß2 (47). 


\section{nAChR a5}

Las subunidades a5 del nAChR se expresan ampliamente en el sistema nervioso central de los mamíferos (48), incluyendo la médula espinal, ganglios de la raíz dorsal de rata, así como periféricamente en ganglios simpáticos y parasimpáticos $(49,50)$.

La subunidad a5 no puede formar un receptor homomérico funcional sola, o ensamblar dentro de los nAChR como única una subunidad expresa, ya sea con subunidad $\beta 2$ o $\beta 4$. Por lo tanto, la subunidad a5 se incorpora con un subtipo de nAChR a $4 \beta 2$, a3 $\beta 2$, y a3 $\beta 4$ donde influye mucho en la modulación de la función del receptor de la nicotina y las propiedades farmacológicas de estos subtipos de receptores en respuesta a la droga en sistemas de expresión heterólogos $(51,52)$. Además, datos recientes apoyan un papel importante del a5 en los efectos conductuales de la nicotina. Estudios realizados por Bagdas et al., mostraron que la supresión genética de subunidades nicotínicas a5 reduce las conductas de dolor, como la hiperalgesia térmica y alodinia mecánica en modelos de dolor inflamatorio y neuropático en ratón (53).

Los ratones nulos para la subunidad a5 del $\mathrm{nAChR}$ han reducido la sensibilidad a las convulsiones y hipolocomoción inducida por la nicotina (54). Además, la antinocicepción inducida epibatidina está completamente ausente en a5-KO ratones (55). Estos ratones KO a5 son menos sensibles a la antinocicepción inducida por la nicotina y la hipotermia en comparación con compañeros de camada WT después de la administración aguda del fármaco en ratones (56).

Están emergiendo datos sobren el posible papel de los nAChR que contienen a5 en la regulación de funciones importantes en el sistema nervioso central, así como el sistema nervioso periférico. Por ejemplo, se informó que estos receptores pueden influir en el control autonómico de varios sistemas de órganos (57). Además, Vincler y Eisenach observaron un incremento en la expresión de la subunidad a5 del nAChR en las láminas exterior del cuerno dorsal después de la ligadura del nervio espinal en ratas. Sin embargo, hacen falta más estudios para determinar con exactitud su rol en el manejo de la analgésica (58).

\section{nAChR a 7}

El subtipo nAChR a7 es un miembro bien caracterizado de la superfamilia de neurotransmisor de canal iónico (59). Además, exhibe distintos perfiles fisiológicos y farmacológicos en relación con otros subtipos de $n A C h R$, que se caracterizan por su alta permeabilidad al calcio, la estructura homopentamérica y la rápida desensibilización después de la activación agonista (60). El nAChR a7 es el tipo de receptor nicotínico más abundante en el sistema nervioso y desempeña múltiples funciones, tales como la memoria, la cognición y la modulación del dolor $(61,62)$.

Recientes trabajos se han centrado en el papel de los nAChR a7 en la modulación de la inflamación y la nocicepción (63). Además de su presencia neuronal, nAChR a7 se expresan en macrófagos, que son células inmunes clave implicadas en la iniciación, mantenimiento y resolución de la inflamación $(64,65)$. Estudios han demostrado la importancia de la acetilcolina que interactúa directamente con los nAChR a7 expresados en los macrófagos y otras células productoras de citoquinas en la regulación negativa de la síntesis de citoquinas proinflamatorias y previenen el daño tisular (66).

Además, los agonistas de los nAChR a7 han recibido mucha atención como posibles objetivos para el dolor y la inflamación en los estudios preclínicos $(67,68)$. Sin embargo, hay desacuerdo sobre el efecto analgésico por la activación del nAChR a7 periférico. Estudios relacionados con los modelos de dolor agudo, reportaron que la activación central y periférica del nAChR a7 reduce la nocicepción y el dolor inflamatorio agudo (69). Pocos estudios, que han tratado con los modelos de inflamación crónica, mostraron que los agonistas del nAChR a7 reducen las señales dolorosas a través de la activación de receptor central y no del receptor periférico (70). Xiao et al., mostraron una sobre regulación de la expresión de nAChR a7 en la raíz del ganglio dorsal de la rata catorce días después de axotomía del nervio ciático (71). Por otra parte, los agonistas de los nAChR a7 provocaron efectos antiinflamatorios y antinociceptivos significativos en modelos de roedores de dolor neuropático crónico y la inflamación (72). 
Un enfoque alternativo para mejorar selectivamente la actividad del nAChR a7 es a través de los moduladores alostéricos positivos (MAP) (73), moléculas que aumentan la respuesta agonista-evocada por la reducción de la energía requerida para un receptor para mover de reposo a estado activo (74). Además, facilitan la neurotransmisión endógena y/o mejoran la eficacia y la potencia de un agonista sin estimular directamente los sitios de unión de agonista (75). En principio, MAP no exhiben actividad intrínseca en el receptor, sin embargo, puede reforzar la neurotransmisión colinérgica endógena sin activar directamente los nAChR a 7 (76).

Los MAP se pueden clasificar en dos categorías: Tipo-I que mejoran la función del receptor pero no afectan a las propiedades de desensibilización y Tipo-II que reducen la desensibilización del receptor, prolongando así la activación del receptor. PNU-120596, un MAP a7 Tipo-II, reduce el comportamiento nociceptivo más eficazmente que NS1738, un MAP a7 Tipo-I, en una variedad de pruebas nociceptivas preclínicas seis horas después de la lesión (77). En otras palabras, PNU-120596, modifica el equilibrio entre los estados activos e insensibilizados resultando en las respuestas significativamente prolongadas, incluso la promoción de la activación de los receptores previamente desensibilizados (78). No es sorprendente la co-aplicación de PNU-120596 con un agonista del nAChR a7 para mejorar los efectos antinociceptivos con relación a ya sea los MAP o solo el agonista a7. Estos datos sugieren que combinado un MAP a7 Tipo II y con la aplicación de un agonista podría ser un tratamiento eficaz para el dolor inflamatorio. Freitas et al., mostraron que mientras NS-1738 y PNU-120596 atenúan la hiperalgesia asociada con la inflamación, solamente PNU-120596 redujo la hiperalgesia y la alodinia en el modelo de dolor neuropático crónico (79).

Munro et al., mostró que PNU-120596 produce efectos antihiperalgésicos en la formalina, carragenano o adyuvante completo de Freund (CFA) en prueba en ratas a través de una disminución en los niveles de TNF-a e IL-6. Y Kelen et al., también mostraron que el efecto del agonista selectivo nAChRs a7 fue similar con el MAP tipo-II en el do- lor neuropático (80). Zhang et al., demostraron que agonistas selectivos del nAChR a7 tanto PHA-543613 y MAP Tipo-II PNU120596 podrían atenuar la hiperalgesia dosis-dependiente inducida por Remifentanilo. Además, mostraron que la combinación de PHA-543613 y PNU-120596 podría producir mejores efectos antihiperalgesia en comparación con cada fármaco administrado solo. También investigaron los niveles de proteína de TNF-a, IL-6 y P-NR2B en la médula espinal, encontrando que la activación del nAChR a7 inhibe la producción de citocinas proinflamatorias y p-NR2B en el cuerno dorsal de la médula. Por este mecanismo, el nAChR a7 puede mejorar inducida remifentanilo hiperalgesia postoperatoria (81).

\section{CONCLUSIÓN}

Los nAChR constan de diferentes subtipos, cada uno de los cuales tiene una farmacología y fisiología específica, con diferente distribución anatómica en el cerebro. Constan de varios complementos de a2-a9 y subunidades $\beta 2-\beta 4$. Actualmente, seis a (a2-a7) y tres $\beta(\beta 2-\beta 4)$ subunidades se han identificado y clonado a partir de cerebro humano y son objetivos viables para el desarrollo de nuevos analgésicos. El nAChR a $4 \beta 2$ es el de mayor distribución en el cerebro, con implicación en la modulación del dolor. La activación presináptica en la medula espinal ejerce inhibición tónica en la transmisión nociceptiva, siendo atractivos para el estudio del dolor neuropático e inflamatorio. Las subunidades a5 del nAChR se expresan ampliamente en el sistema nervioso central jugando un papel muy importante en las vías del dolor. Por su parte, nAChR a7 es el tipo de receptor nicotínico más abundante en el sistema nervioso y desempeña múltiples funciones, participando en la iniciación, mantenimiento y resolución de la inflamación. Pese a todos estos hallazgos, hacen falta más estudios para determinar con exactitud el rol de los nAChR en la fisiopatología y terapeutica del dolor.

CONFLICTOS DE INTERESES: ninguno que declarar.

FINANCIACIÓN: recursos propios de los autores. 


\section{REFERENCIAS BIBLIOGRÁFICAS}

1. Umana I, Daniele C, McGehee D. Neuronal nicotinic receptors as analgesic targets: It's a winding road. Biochemical Pharmacology. 2013;86:1208-14.

2. Brandt $D$. The cigarette century: the rise, fall and deadly persistence of the product that defined America. J of Popular Culture. 2008;(41)5:893-4.

3. Corti C. A history of smoking. London: George C. Harrap. 2007.

4. Hurts R, Rollema H, Bertrand D. Nicotinic acetylcholine receptors: From basic science to therapeutics. Pharmacology \& Therapeutics 2013;137(2):22-54.

5. Davis L, Pollock LJ, Stone T. Visceral pain. Surgery Gynecology and Obstetrics $1932 ; 55(2): 418-27$.

6. Criado M. El receptor nicotínico de acetilcolina. Instituto de Neurociencias, Sant Joan d'Alacant, Alicante, España. 2011.

7. Flores M, Segura J. Estructura y función de los receptores acetilcolina de tipo muscarínico y nicotínico. Rev Mex Neuroci 2005;6(4):315-26.

8. Díaz M, Gualix J, Gómez R, Castro R, Pintor J, Miras Portugal MT. Receptores nicotínicos neurales: interacción con receptores purinérgicos. Anal Real Acad Farm. 2000; 66(1):121.

9. Devillers-Thiéry A, Galzi JL, Eiselé JL, Bertrand S, Changeux JP. Functional architecture of the nicotinic acetylcholine receptor: a prototype of ligand-gated ion channels. J. Membr. Biol. 1993;136:97-112.

10. Karlin, A. and Akabas, M. H. Toward a structural basis for the function of nicolinic acetylcholine receptors and their cousins. Neuron. 1995;15:1231-44.

11. Paterson D, Nordberg A. Neuronal nicotinic receptors in the human brain. Progress in Neurobiology. 2000;61:75-111.

Gotti C, Fornasari D, Clementi F. Human neuronal nicotinic receptors. Prog Neurobiol. 1997;53:199-37.

12. Sargent PB. The diversity of neuronal nicotinic acetylcholine receptors. Annu. Rev. Neurosci. 1993;16:403-43.

13. Elgoyhen A B, Johnson DS, Boulter J, Vetter DE, Heinemann S. a9: An acetylcholine receptor with novel pharmacological properties expressed in rat cochlear hair cells. Cell. $1994 ; 79: 705-15$.

14. Galzi JL, Changeux JP. Neuronal nicotinic receptors: molecular organization and regulations. Neuropharmacology.1995;34:563-82.

15. Luetje CW, PatrJck J. Both OE- and /J-subunits contribute to the agonist sensitivity of neuronal nicotinic acetylcholine receptors. J Neurosci. 1991;11: 837-45.

16. Levin ED, Simon BB. Nicotinic acetylcholine involvement in cognitive function in animals. Psychopharmacology. 1998;138:217-30.

17. Cartaud J, Benedetti E.L, Cohen J.B, Meunier J.C, Changeux J.P. Presence of a lattice structure in membrane fragments rich in nicotinic receptor protein from the electric organ of Torpedo marmorata. FEBS Lett. 1973;33:109-13.

18. Sargent P.B. The diversity of neuronal nicotinic acetylcholine receptors. Annu Rev Neurosci. 1993;16:403-43.

19. Hogg RC, Bertrand D. Partial agonists as therapeutic agents at neuronal nicotinic acetylcholine receptors. Biochem Pharmacol. 2007;73:459-68.

20. Iwamoto ET. Characterization of the antinociception induced by nicotine in the pedunculopontine tegmental nucleus and the nucleus raphe magnus. J Pharmacol Exp Ther. $1991 ; 257: 120-33$.

21. Conroy WG, Vernallis AB, Berg DK. The alpha 5 gene product assembles with multiple acetylcholine receptor subunits to form distinctive receptor subtypes in brain. Neuron. 1992;9:679-91.

22. Couturier S, Bertrand D, Matter J.M, Hernandez M.C, Bertrand S, Millar N, Valera S, Barkas T, Ballivet M. A neuronal nicotinic acetylcholine receptor subunit (alpha 7) is developmentally regulated and forms a homo-oligomeric channel blocked by alpha-BTX. Neuron. 1990;5:847-56.

23. Ballantyne JC, Shin NS. Efficacy of opioids for chronic pain: a review of the evidence. Clinical J of Pain. 2008;24:469-78.

24. Hamann SR, Martin WR. Opioid and nicotinic analgesic and hyperalgesic loci in the rat brain stem. J of Pharmacology and Experimental Therapeutics. 1992; 261:707-15.

25. Sahley TL, Berntson GG. Antinociceptive effects of central and systemic administrations of nicotine in the rat. Psychopharmacology. 1979;65:279-83.

26. Fertig JB, Pomerleau OF, Sanders B. Nicotine-produced antinociception in minimally deprived smokers and ex-smokers. Addictive Behaviors. 1986;11: 239-48.

27. Henningfield JE, Miyasato K, Jasinski DR. Abuse liability and pharmacodynamic characteristics of intravenous and inhaled nicotine. J of Pharmacology and Experimental Therapeutics. 1985;234:1-12.

28. Kottke TE, Brekke ML, Solberg LI, Hughes JR. A randomized trial to increase smoking 
intervention by physicians. Doctors helping smokers, Round I. JAMA 1989;261:2101-6.

29. Cepeda-Benito A, Reynoso J, McDaniel EH. Associative tolerance to nicotine analgesia in the rat: tail-flick and hot-plate tests. Experimental and Clinical Psychopharmacology. 1998; 6(2):248-54.

30. Hogg R.C, Raggenbass M, Bertrand D. Nicotinic acetylcholine receptors: from structure to brain function. Rev. Physiol. Biochem. Pharmacol. 2003;147:1-46.

31. Marubio L.M, del Mar Arroyo-Jimenez $M$, Cordero-Erausquin $M$, Léna $C$, Le Novère $N$, de Kerchove d'Exaerde A, Huchet M, Damaj M.I, Changeux J.P. Reduced antinociception in mice lacking neuronal nicotinic receptor subunits. Nature. 1999;398(5):805-10.

32. Damaj MI, Fonck C, Marks MJ, Deshpande P, Labarca C, Lester HA, Collins AC, Martin BR. Genetic approaches identify differential roles for a4 $\beta 2$ nicotinic receptors in acute models of antinoniception in mice. J. Pharmacol Exp Ther. 2007;321:1161-9.

33. Shi Y, Weingarten TN, Mantilla CB, Hooten WM, Warner DO. Smoking and pain: pathophysiology and clinical implications. Anesthesiology 2010;113:977-92.

34. Sher E, Chen Y, Sharples TJ, Broad LM, Benedetti G, Zwart R, McPhie GI, Pearson KH, Baldwinson T, De Filippi G. Physiological roles of neuronal nicotinic receptor subtypes: new insights on the nicotinic modulation of neurotransmitter release, synaptic transmission and plasticity. Curr Top Med. Chem. 2004;4:283-97.

35. Nigori R, Jayarajan P, Abraham R, Shanmuganathan D, Rasheed M, Royapalley P, Goura $V$. Antinociceptive activity of a4 $32 *$ neuronal nicotinic receptor agonist A-366833 in experimental models of neuropathic and inflammatory pain. European J of Pharmacology. 2011;668:155-62

36. Kesingland AC, Gentry CT, Panesar MS, Bowes MA, Vernier JM, Cube R, Walker K, Urban $\mathrm{L}$. Analgesic profile of the nicotinic acetylcholine receptor agonists, (+)-epibatidine and ABT-594 in models of persistent inflammatory and neuropathic pain. Pain. 2000;86:11318.

37. Lynch JJ, Wade CL, Mikusa JP, Decker MW, Honore P. ABT-594 (a nicotinic acetylcholine agonist): antiallodynia in a rat chemotherapy-induced pain model. European J Pharmacol. 2005;509:43-8.

38. Galindo L, Hernández S, Galarraga E, Tapia D, Bargas J, Garduño J, Frías C, Drucker R, Mihailescu S. Serotoninergic dorsal raphe neurons possess functional postsynaptic nicotinic acetylcholine receptors. Synapse. 2008;62: 601-15.

39. Nakamura M, Jang S. Presynaptic nicotinic acetylcholine receptors enhance GABAergic synaptic transmission in rat periaqueductal gray neurons. European J of Pharmacology. 2010:640:178-84.

40. Bitner R.S, Nikkel A.L, Curzon P, Donnelly-Roberts D.L, Puttfarcken P.S, Namovic M, Jacobs I.C, Meyer M.D, Decker M.W. Reduced nicotinic receptor-mediated antinociception following in vivo antisense knock-down in rat. Brain Res. 2000;871:66-74.

41. Cucchiaro G, Chaijale N, Commons K.G. The dorsal raphe nucleus as a site of action of the antinociceptive and behavioral effects of the a4 nicotinic receptor agonist epibatidine. J Pharmacol Exp Ther. 2005;313:389-94.

42. Rashid $\mathrm{MH}$, Furue $\mathrm{H}$, Yoshimura $\mathrm{M}$, Ueda $\mathrm{H}$. Tonic inhibitory role of alpha 4 beta 2 subtype of nicotinic acetylcholine receptors on nociceptive transmission in the spinal cord in mice. Pain. 2006;125:125-35.

43. Li X, Eisenach JC. Nicotinic acetylcholine receptor regulation of spinal norepinephrine release. Anesthesiology. 2002;96:1450-56.

44. Genzen R, McGehee D.S. Nicotinic modulation of GABAergic synaptic transmission in the spinal cord dorsal horn. Brain Res. 2005;1031:229-37.

45. Matsunaga K, Klein TW, Friedman H, Yamamoto Y. Involvement of nicotinic acetylcholine receptors in suppression of antimicrobial activity and cytokine responses of alveolar macrophages to Legionella pneumophila infection bynicotine. J Immunol. 2001;167:651824.

46. Hosur V, Leppanen S, Abutaha A, Loring R.H. Gene regulation of a4 $\beta 2$ nicotinic receptors: microarray analysis of nicotine-induced receptor up-regulation and anti-inflammatory effects. J Neurochem. 2009;111:848-58.

47. Heinemann S, Boulter J, Deneris E, Conolly J, Duvoisin R, Papke R. The brain nicotinic acetylcholine receptor gene family. Prog Brain Res. 1990;86:195-203.

48. Vincler M.A, Eisenach J.C. Immunocytochemical localization of the alpha3, alpha4, alpha5, alpha7, beta2, beta3 and beta4 nicotinic acetylcholine receptor subunits in the locus coeruleus of the rat. Brain Res. 2003;974:25-36.

49. De Biasi M. Nicotinic receptor mutant mice in the study of autonomic function. Curr. Drug Targets CNS Neurol. Disord. 2002;1:331-36.

50. Ramirez-Latorre J, Yu C.R, Qu X, Perin F, Karlin A, Role L. Functional contributions of alpha5 subunit to neuronal acetylcholine receptor channels. Nature. 1996;380:347-51.

51. Tapia L, Kuryatov A, Lindstrom J. Ca2+ permeability of the (alpha4)3(beta2)2 stoichiometry greatly exceeds that of (alpha4)2(beta2)3 human acetylcholine receptors. Mol. Pharmacol. 2007;71:769-76.

52. Bagdas D, AISharari S, Freitas K, Tracy M, Imad Damaj M. The role of alpha5 nicotinic 
acetylcholine receptors in mouse models of chronic inflammatory and neuropathic pain. Biochemical Pharmacology. 2015. doi: 10.1016/j.bcp.2015.04.013.

53. Salas R, Orr-Urtreger A, Broide R.S, Beaudet A, Paylor R, De Biasi M. The nicotinic acetylcholine receptor subunit alpha 5 mediates short-term effects of nicotine in vivo. Mol. Pharmacol. 2003;63:1059-66.

54. Jackson KJ, Marks MJ, Vann RE, Chen X, Gamage TF, Warner JA, et al. Role of alpha5 nicotinic acetylcholine receptors in pharmacological and behavioral effects of nicotine in mice. Journal of Pharmacology and Experimental Therapeutics. 2010;334:137-46.

55. Salas R, Sturm R, Boulter J, De Biasi M. Nicotinic receptors in the habenulointerpeduncular system are necessary for nicotine withdrawal in mice. J. Neurosci. 2009;29:3014-18.

56. Wang N, Orr-Urtreger A, Chapman J, Rabinowitz R, Nachman R, Korczyn A.D. Autonomic function in mice lacking alpha5 neuronal nicotinic acetylcholine receptor subunit. J. Physiol. 2002;542:347-54.

57. Vincler M, Eisenach J.C. Plasticity of spinal nicotinic acetylcholine receptors following spinal nerve ligation. Neurosci. Res. 2004;48:139-45.

58. Lukas R.J, Changeux J.P, Le Nove` re N, Albuquerque E.X, Balfour D.J, Berg D.K, et al. International Union of Pharmacology. XX. Current status of the nomenclature for nicotinic acetylcholine receptors and their subunits. Pharmacol Rev. 1999;51:397-401.

59. Shen JX, Yakel JL. Nicotinic acetylcholine receptor-mediated calcium signaling in the nervous system. Acta Pharmacol Sin. 2009;30(6):673-80.

60. Feuerbach D, Lingenhoehl K, Olpe H.R, Vassout A, Gentsch C, Chaperon F, Nozulak J, Enz A, Bilbe G, McAllister K, Hoyer D. The selective nicotinic acetylcholine receptor alpha7 agonist JN403 is active in animal models of cognition, sensory gating, epilepsy and pain. Neuropharmacology. 2009;56:254-63.

61. Kiguchi , Kobayashi Y, Maeda T, Tominaga S, Nakamura J, Fukazawa Y, Ozaki M, Kishioka S. Activation of nicotinic acetylcholine receptors on bone marrow-derived cells relieves neuropathic pain accompanied by peripheral neuroinflammation. Neurochem Int. 2012;61:1212-19.

62. Westman M, Saha S, Morshed M, Lampa J. Lack of acetylcholine nicotine alpha 7 receptor suppresses development of collagen-induced arthritis and adaptive immunity. Clin Exp Immunol. 2010;162:62-7.

63. Fujiwara N, Kobayashi K. Macrophages in inflammation. Curr Drug Targets Inflamm Allergy. 2005;4:281-86.

64. Ulloa $\mathrm{L}$. The vagus nerve and the nicotinic anti-inflammatory pathway. Nat Rev Drug Discov. 2005;4:673-84.

65. De Rosa MJ, Dionisio L, Agriello E, Bouzat C, Esandi MC. Alpha 7 nicotinic acetylcholine receptor modulates lymphocyte activation. Life Sci. 2009;85:444-49.

66. Thomsen MS, Hansen HH, Timmerman DB, Mikkelsen JD. Cognitive improvement by activation of a7 nicotinic acetylcholine receptors: from animal models to human pathophysiology. Curr Pharm Des. 2010;16:323-43.

67. Rowley TJ, McKinstry A, Greenidge E, Smith W, Flood P. Antinociceptive and anti-inflammatory effects of choline in a mouse model of postoperative pain. $\mathrm{Br}]$ Anaesth. 2010;105(2):201-7.

68. Munro G, Hansen R, Erichsen H, Timmermann D, Christensen J, Hansen H. The alpha7 nicotinic ACh receptor agonist compound B and positive allosteric modulator PNU-120596 both alleviate inflammatory hyperalgesia and cytokine release in the rat. $\mathrm{Br} \mathrm{J}$ Pharmacol. 2012;167:421-35.

69. Medhurst S.J, Hatcher J.P, Hille C.J, Bingham S, Clayton N.M, Billinton A, Chessell I.P. Activation of the alpha7-nicotinic acetylcholine receptor reverses complete freund adjuvant-induced mechanical hyperalgesia in the rat via a central site of action. J Pain. 2008;9:580-87.

70. Xiao HS, Huang QH, Zhang FX, Bao L, Lu YJ, Guo C, Yang L, Huang WJ, Fu G, Xu S.H, et al. Identification of gene expression profile of dorsal root ganglion in the rat peripheral axotomy model of neuropathic pain. Proc Natl Acad Sc. 2002:12;8360-65.

71. Gurun MS, Parker R, Eisenach JC, Vincler M. The effect of peripherally administered CDPcholine in an acute inflammatory pain model: the role of alpha7 nicotinic acetylcholine receptor. Anesth Analg. 2009:108;1680-87.

72. Freitas K, Ghosh S, Ivy Carroll F, Lichtman A, Damaj M. Effects of alpha 7 positive allosteric modulators in murine inflammatory and chronic neuropathic pain models. Neuropharmacology. 2013;65:156-64.

73. Bertrand D, Gopalakrishnan M. Allosteric modulation of nicotinic acetylcholine receptors. Biochemical Pharmacology. 2007;74:1155-63.

74. Faghih R, Gfesser G.A, Gopalakrishnan M. Advances in the discovery of novel positive allosteric modulators of the alpha7 nicotinic acetylcholine receptor. Recent Pat CNS Drug Discov. 2007;2:99-106.

75. Faghih R, Gopalakrishnan M, Briggs C.A. Allosteric modulators of the alpha7 nicotinic acetylcholine receptor. J Med Chem. 2008;51:701-12.

76. Timmermann DB, Grønlien JH, Kohlhaas KL, Nielsen EØ, Dam E, Jørgensen TD. et al. An 
allosteric modulator of the a 7 nicotinic acetylcholine receptor possessing cognition-enhancing properties in vivo. J Pharmacol Exp Ther. 2007;323:294-307.

77. Grønlien JH, Håkerud M, Ween H, Thorin-hagene K, Briggs C.A, Gopalakrishnan M, Malysz J. Distinct profiles of a7 nAChR positive allosteric modulation revealed by structurally diverse chemotypes. Mol Pharmacol. 2007;72:715-24.

78. Freitas K, Negus SS, Carroll FI, Damaj MI. In vivo pharmacological interactions between a type II positive allosteric modulator of a7 nicotinic ACh receptors and nicotinic agonists in a murine tonic pain model. British J of Pharmacology. 2013;169:567-79.

79. Gao YJ and Ji RR. Chemokines, neuronal-glial interactions, and central processing of neuropathic pain. Pharmacol Ther. 2010;26:56-68.

80. Zhang W, Liu Y, Hou B, Gu X, Ma Z. Activation of spinal alpha-7 nicotinic acetylcholine receptor attenuates remifentanil-induced postoperative hiperalgesia. Int J Clin Exp Med. 2015;8(2):187179.

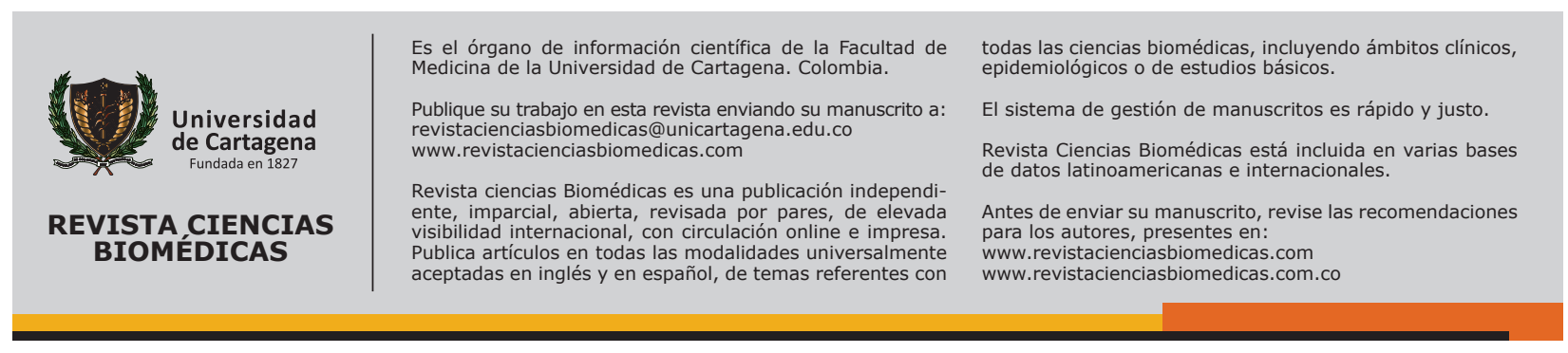

